\title{
Comparative Study on Properties of Polylactic Acid Nanocomposites with Cellulose and Chitin Nanofibers Extracted from Different Raw Materials
}

\author{
Jingjing Li, ${ }^{1}$ Jian Li, ${ }^{1}$ Dejun Feng, ${ }^{1}$ Jingfeng Zhao, ${ }^{1}$ Jingrong Sun, ${ }^{1}$ and Dagang $\mathrm{Li}^{2}$ \\ ${ }^{1}$ College of Forestry, Northwest A\&F University, Yangling, China \\ ${ }^{2}$ College of Materials Science and Engineering, Nanjing Forestry University, Nanjing, China
}

Correspondence should be addressed to Dagang Li; 396420748@qq.com

Received 15 May 2017; Revised 17 September 2017; Accepted 16 October 2017; Published 20 November 2017

Academic Editor: Mangala Joshi

Copyright (C) 2017 Jingjing Li et al. This is an open access article distributed under the Creative Commons Attribution License, which permits unrestricted use, distribution, and reproduction in any medium, provided the original work is properly cited.

Polylactic acid (PLA) was reinforced with ultralong cellulose and chitin nanofibers extracted from four raw materials by extrusion. The mechanical, rheological, thermal, and viscoelastic performances of four nanocomposites were comparatively studied in detail. The results showed that fibrillation of poplar was much easier than that of cotton, and fibrillation of crab shell was relatively hard as compared to prawn shell. The poplar CNFs/PLA composite exhibited the best mechanical properties among four nanocomposites due to the highest aspect ratio of nanofibers, while both the cotton CNFs/PLA composite and the crab shell CHNFs/PLA composite had low mechanical strength due to the relatively low aspect ratio. FE-SEM images showed that the ultralong nanofibers were uniformly dispersed in PLA matrix for all four samples with the water preblending method. The CTE values of the nanocomposites with $40 \mathrm{wt} \%$ nanofibers extracted from poplar, cotton, crab shell, and prawn shell were $69.5 \times 10^{-6} \mathrm{~K}^{-1}, 79.6 \times 10^{-6} \mathrm{~K}^{-1}$, $77.2 \times$ $10^{-6} \mathrm{~K}^{-1}$, and $75.3 \times 10^{-6} \mathrm{~K}^{-1}$, respectively. All the results indicated that the aspect ratio of the nanofibers has a great influence on the performance of the composites, irrespective of the composites prepared by cellulose or chitin.

\section{Introduction}

Polylactic acid (PLA) is a renewable, biocompatible, and biodegradable polymer and it is one of the most widely used bioplastics [1]. Due to the excellent modulus and tensile strength and high transparency comparable to petroleumbased polymers, PLA is a good alternative for the conventional synthetic polymers in different applications, especially in packaging [2]. Nevertheless, the properties of PLA such as thermal stability and impact toughness are inferior to those of conventional polymers used for thermoplastic applications [3]. To overcome the mentioned drawbacks and broaden the application areas of PLA, considerable researches have been carried out to develop and study modified PLA, PLA-based copolymers, and PLA-based composites [4].

Cellulose nanofibers (CNFs) and chitin nanofibers (CHNFs) have attracted the attention of researches as additives in the green nanocomposites field because they are biodegradable and renewable polymers with good mechanical properties. CNFs have highly ordered crystalline regions alternating with disordered amorphous domains [5]. The crystalline regions of CNFs have a high Young's modulus of $138 \mathrm{GPa}$ [6] and a very low thermal expansion coefficient $\left(10^{-7} \mathrm{~K}^{-1}\right.$ in the longitudinal direction) [7]. As the second most abundant natural polysaccharide after cellulose, chitin is the major structural component of cell walls in fungi and yeast, the exoskeleton of arthropods, and mollusk shells [8]. It is reported that the longitudinal modulus and the transverse modulus of chitin nanocrystals are $150 \mathrm{GPa}$ and $15 \mathrm{GPa}$, respectively [9]. Because of these distinctive properties, $\mathrm{CNF} / \mathrm{CHNFs}$ have been used in a wide range of applications such as optically transparent materials, reinforced polymer nanocomposites, biomimetic foams, multifunctional fibers, templates for chiral nematic mesoporous materials, and conductive materials [10]. 
Cellulose nanomaterials have been extensively used as an additive to improve the thermal, mechanical, and barrier properties of PLA [11-17]. However, most of the literature has focused on the NCC or MCC (microcrystal cellulose) reinforced PLA composites. There is a lack of study on the CNFs with high aspect ratio reinforced PLA composites due to the dispersion problem of the ultralong CNFs. In addition, chitin nanofibers are mainly used in other polymers, such as poly (caprolactone), chitosan, PVA, PMMA, and starch [14], while the research on chitin nanofibers reinforced PLA is very rare [18].

Although CNFs and CHNFs have great potential as reinforcements, the uniform dispersion in polymer matrix is the major challenge. It is well known that materials in nanosize have a strong tendency to aggregate. In addition, the strong hydrogen bonds form when cellulose and chitin are dried, leading to the aggregation problem. To overcome the dispersion and compatibility difficulties, cellulose/chitin nanofibers have been subjected to physical treatments and chemical modification [19]. However, the mechanical properties of the prepared nanocomposites are not remarkably improved due to the damaged molecular structure of nanofibers by chemical modification.

Until now, the preparation of CNFs/CHNFs reinforced polymer composites is mainly focused on the methods of solvent casting, freeze-drying, and electrospinning. The development of more flexible and viable processing techniques for industrial applications is needed to promote the commercialization of nanofibers-based composites. Among the processing techniques, the melt-compounding process is the most potential technique, since the final product prepared by this technique can be easily shaped [13]. However, there are only very few studies on the nanocomposite prepared by the melt-compounding technique, especially in the case of chitin nanofibers $[20,21]$.

In this study, four different CNFs/CHNFs reinforced PLA composites were prepared using the extrusion process. The CNFs/CHNFs were extracted from the raw materials of poplar flour, cotton, crab shell, and prawn shell. All the isolated CNFs/CHNFs showed network structure and high aspect ratio. The effects of fiber morphology on the mechanical, thermal, and viscoelastic properties of the prepared nanocomposites were comparatively investigated to evaluate the reinforcing effect of CNFs and CHNFs. To solve the dispersion problem of ultralong CNFs/CHNFs in PLA matrix, the PLA powders were premixed with the CNFs/CHNFs water slurry followed by freeze-drying before the nanocomposites were extruded. This process is a time-saving and environmentally friendly method due to the absence of chemical reagent.

\section{Materials and Methods}

2.1. Materials. Polylactic acid (PLA), NatureWorks TM 4032D, was supplied by Nanjing Jufeng Advanced Materials Co., Ltd. (Nanjing, China). The glass transition temperature $\left(T_{g}\right)$ and melting point $\left(T_{m}\right)$ were $55^{\circ} \mathrm{C}$ and $180^{\circ} \mathrm{C}$, respectively. The melt flow index (MFI) was $6 \mathrm{~g} / 10 \mathrm{~min}\left(190^{\circ} \mathrm{C}\right.$,
$2.16 \mathrm{~kg}$ ). The poplar flour with the size of $60-80$ mesh was obtained from Nanjing Jufeng Advanced Materials Co., Ltd. (Nanjing, China). Absorbent cotton, medical grade, was purchased from Beijing Tianheng Bohao Medical Equipment Co., Ltd. (Beijing, China). Dried crab shell powder and prawn shell powder were obtained from Golden Shell Biochemical Co., Ltd. (Zhejiang, China). The other chemicals and distilled water were purchased from Nanjing Chemical Reagent Company and used without further purification in this study (Nanjing, China).

2.2. Preparation of Poplar CNFs. Based on our previously reported methods [22], the preparation procedure of poplar CNFs was mainly divided into chemical pretreatment and grinding nanofibrillation. After chemical treatment, the water slurry with $1 \mathrm{wt} \% \mathrm{CNF}$ s was passed through a grinder (MKCA6-2, Masuko Sangyo Co., Japan) for 20 times with the grinding stone at $1800 \mathrm{rpm}$.

2.3. Preparation of Cotton CNFs. The preparation of cotton CNFs was conducted according to our previously reported methods [23]. The extraction process of cotton CNFs was simpler than that of poplar CNFs due to higher cellulose content in cotton.

2.4. Preparation of Crab/Prawn CHNFs. Crab/prawn shells are composed of chitin and some other constituents such as proteins, lipids, calcium carbonate, and pigments. The chemical treatment of crab/prawn shell was conducted according to our previously reported methods [24]. Finally, a water suspension with $1 \mathrm{wt} \%$ CHNFs was passed through the grinder for 20 times with the grinding stone at $1800 \mathrm{rpm}$.

2.5. Preparation of Nanofibers/PLA Composites. Before the extrusion process, different contents of PLA powders (60-80 mesh) were added to the $1 \mathrm{wt} \%$ CNFs/CHNFs water slurry and were continuously stirred by a magnetic stirrer at $75^{\circ} \mathrm{C}$ for $1 \mathrm{~h}$. After the water preblending process, the mixture slurry was dehydrated by vacuum filtration using a Büchner funnel and then was freeze-dried. Subsequently, the nanofibers/PLA mixture was fully broken using a blender and fed into a HAAKE MiniLab (HAAKE MiniLab II, Thermo Fisher Scientific, Germany) for compounding. The HAAKE MiniLab is a small twin screw extruder for laboratory use. The samples were extruded through a rectangular die with the sectional dimension of $3.5 \times 1 \mathrm{~mm}^{2}$. The samples were crushed into powder by a blender and then hot-pressed at $170^{\circ} \mathrm{C}$ for $5 \mathrm{~min}$ with a press vulcanizer.

\subsection{Characterization}

\section{Cellulose/Chitin Nanofibers}

FE-SEM. The morphologies of four different nanofibers were observed using a field emission scanning electron microscope (HITACHI S-4860, HITACHI, Japan). Prior to FE-SEM observations, the samples were kept in a vacuum oven at $30^{\circ} \mathrm{C}$ overnight and then coated with gold for $30-60 \mathrm{~s}$ to avoid 
charging. The acceleration voltage was $3 \mathrm{kV}$ and the coating current was $10 \mathrm{~mA}$. The width of nanofibers was measured using a microscope image analysis system, Image-Pro Plus.

\section{CNFs/CHNFs Reinforced PLA Composites}

Rheological Properties. The nanofibers/PLA mixture was fed into the HAAKE MiniLab for capillary rheological test. The extrusion temperature was set at $180^{\circ} \mathrm{C}$. The rotating screw speed was set from $10 \mathrm{rpm}$ to $100 \mathrm{rpm}$. After the rheological measurement, the mixture was extruded through the die. The rotating screw speed was fixed at $40 \mathrm{rpm}$ in the extrusion process.

FE-SEM. The fracture surfaces of four different nanofibers/PLA composites were observed by a FE-SEM. The nanocomposite samples were frozen in liquid nitrogen and then quickly broken.

Mechanical Properties. The tensile and flexural properties of different nanofibers/PLA composites were tested using a universal materials testing machine (AG-10TA, Shimadzu, Japan). The tensile gauge length was fixed at $25 \mathrm{~mm}$ at a tensile speed of $1 \mathrm{~mm} / \mathrm{min}$. Each sample was prepared with a dumbbell shape and dimensions of $50 \mathrm{~mm}$ length, $3 \mathrm{~mm}$ width, and $3 \mathrm{~mm}$ thickness. The flexural properties were tested in bending mode with the span of $40 \mathrm{~mm}$ and the cross head speed of $1 \mathrm{~mm} / \mathrm{min}$ following ASTM-D 790-2010. The results represent the average value of six specimens for each formulation.

The impact strength of different nanofibers/PLA composites was measured by an Izod impact test machine (QJBCX, Shanghai Qingji Instrumentation Technology Co., China) according to ASTM D256-2010. Moreover, at least four replications were tested for each measurement.

Coefficient of Thermal Expansion (CTE). The CTE values of different nanofibers/PLA composites were measured using a thermal mechanical analyzer (TMA 401F1, NETZSCH, Germany) to investigate the change in length with the increase of temperature. The samples were tested in tension mode with a static load of $1 \mathrm{~N}$ and the dimension of $15 \mathrm{~mm} \times$ $5 \mathrm{~mm} \times 1 \mathrm{~mm}$. The tests were performed over the temperature range from -20 to $110^{\circ} \mathrm{C}$ at a heating rate of $5^{\circ} \mathrm{C} / \mathrm{min}$.

Dynamic Mechanical Analysis (DMA). Dynamic mechanical analysis of different nanofibers/PLA composites was performed on a dynamic mechanical analyzer (DMA 242C, NETZSCH, Germany). Prior to the test, the samples were cut into strips with dimension of $32 \mathrm{~mm} \times 3.5 \mathrm{~mm} \times 1 \mathrm{~mm}$. The tests were carried out in a dual cantilever mode at a heating rate of $3^{\circ} \mathrm{C} / \mathrm{min}$ over the temperature range from -20 to $110^{\circ} \mathrm{C}$.

\section{Results and Discussion}

\subsection{Cellulose/Chitin Nanofibers}

FE-SEM. The SEM images of poplar CNFs, cotton CNFs, crab shell CHNFs, and prawn shell CHNFs after the grinding treatment are shown in Figure 1. A classical web-like network structure is observed in all the nanofibers. Moreover, a very long entangled cellulosic filament can be found. The fibers of poplar CNFs in Figure 1(a) are highly uniform even over an extensive area, with the average width of approximately 30-80 $\mathrm{nm}$. The SEM observation also reveals that the length of most obtained poplar CNFs is a few microns. Hence the aspect ratio of poplar CNFs is up to 500-2000. Compared to poplar CNFs, the morphology of cotton CNFs is very different (Figure 1(b)). Although long and single-cellulose nanofiber can be clearly observed, many large fiber bundles are still present. Therefore, the grinder treatment is unable to fibrillate the cotton fibers into nanofibers with a uniform width because of the remaining strong hydrogen bonding within the adjacent cotton cellulose after the chemical purification [25]. Figure 1(c) displays the morphology of crab shell CHNFs after removal of the protein and mineral matrix components. It can be noticed that crab shell could not be uniformly nanofibrillated as compared to the poplar CNFs. The widths of the fibers derived from crab shell are in a range from 120 to $200 \mathrm{~nm}$. The thick fibers corresponding to bundles of nanofibers of $10-20 \mathrm{~nm}$ in width were not successfully fibrillated by the grinding treatment. Compared to crab shell, the CHNFs extracted from prawn shell using the same treatment are relatively uniform over an extensive area, and the width of the nanofibers is $80-120 \mathrm{~nm}$ (Figure $1(\mathrm{~d})$ ). Fibrillation of the prawn shell was relatively easy as compared to crab shell due to the differences in the cuticle structure and fiber thickness. Prawn is primarily made up of a fine exocuticle, while crab shell is mainly composed of the endocuticle, which has a much coarser matrix structure with a thicker fiber diameter than exocuticle [26].

Diameter Distribution. Figure 2 presents the diameter distribution of four different nanofibers after the grinding treatment. In Figure 2(a), the percentage of the poplar CNFs with the width of $30-80 \mathrm{~nm}$ is about $65 \%$. The percentage of the cotton CNFs with the width of $120-500 \mathrm{~nm}$ is approximately $80 \%$ (Figure 2(b)). These results show that cotton CNFs have much thicker fiber bundles as compared to the poplar CNFs. It is very difficult for cotton to fibrillate into nanofibers with a uniform width by the only grinding treatment. Other mechanical processes are necessary to break the strong hydrogen bonding and individualize cotton fibers into much finer nanofibers. For the crab shell CHNFs, the percentages of nanofibers with widths of 120-200 nm and 80-120 nm are about $50 \%$ and $24 \%$, respectively (Figure $2(\mathrm{c})$ ). In contrast, the percentages of prawn shell CHNFs with the widths of $120-200 \mathrm{~nm}$ and $80-120 \mathrm{~nm}$ are $23 \%$ and $52 \%$, respectively. The data suggests that fibrillation of prawn shell is easier than that of crab shell.

\subsection{CNFs/CHNFs Reinforced PLA Composites}

Rheological Properties. Figure 3 presents the capillary rheological curves in terms of the viscosity and shear stress of four nanofibers (40 wt\%)/PLA composite melts as functions of shear rate. All samples show a shear-thinning behavior without a plateau region and a less frequency-dependency behavior, especially at lower frequencies. The shear-thinning 


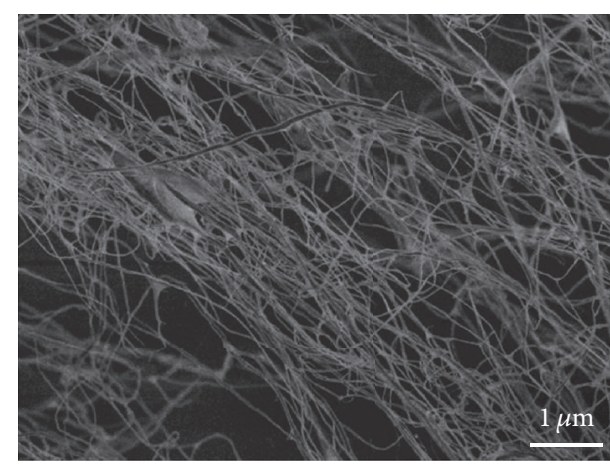

(a)

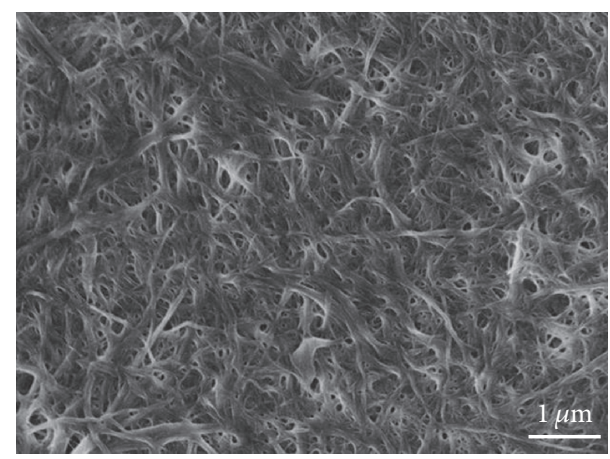

(c)

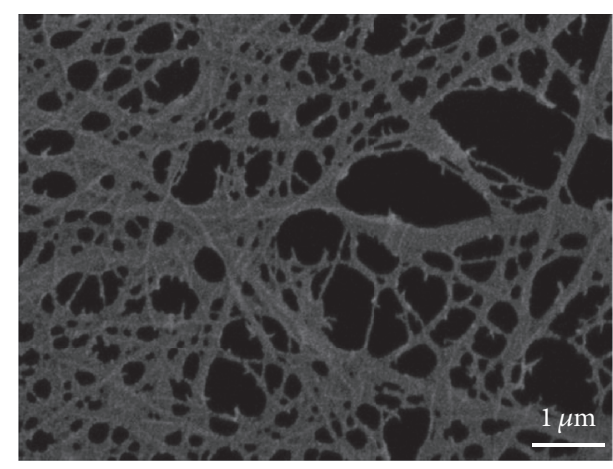

(b)

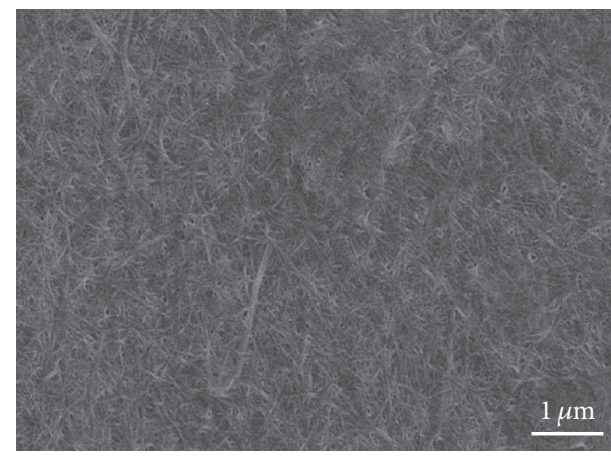

(d)

FIGURE 1: FE-SEM micrographs of the nanofibers extracted from original (a) poplar, (b) cotton, (c) crab shell, and (d) prawn shell.

behavior can be attributed to disentanglement and orientation of nanofibers and PLA chains in the flow direction reducing the viscous resistance. In addition, the viscosity and shear stress of four composites are much higher than those of the pure PLA, suggesting a network formation with the addition of cellulose/chitin nanofibers. Nanofibers will disturb the normal flow of the matrix melt and hinder the mobility of chain segments of polymers. It can also be noticed that the viscosity and shear stress of the poplar CNFs/PLA composite are highest among four samples, and the corresponding values of the cotton/PLA composite are the lowest. According to the SEM images in Figure 1, poplar CNFs have higher aspect ratio, more refined structure, and larger specific surface area than other nanofibers extracted from cotton and crab/prawn shell. Consequently, much stronger CNF/PLA interactions and restriction to PLA chain mobility are generated, leading to the relatively high viscosity and shear stress. It was reported that, in addition to the interfacial interactions through molecular entanglement and mechanical interlocking between nanofibers and the polymer matrix [27], CNFs may have electrostatic attractions with PLA as well $[28,29]$. The cotton/crab shell nanofibers are more easily aligned and distributed along the direction of flow due to the relatively low aspect ratio. Hence, the probability of fiber/fiber collisions is much less than that of the poplar CNFs composite, leading to the lower viscosity and shear stress of the nanocomposites.
Mechanical Properties. Generally, mechanical properties are the key factors in determining the reinforcing effect of nanofibers for PLA. The effect of nanofiber content on the tensile, flexural, and impact properties of four nanofibers/ PLA composites is presented in Figure 4. The tensile strength of PLA is increased slightly with the addition of $10 \mathrm{wt} \%$ nanofibers due to the high stiffness of the nanofiber itself. As shown in Figure 4(a), the tensile strength of nanocomposites increases with increasing nanofiber content up to $30 \mathrm{wt} \%$. However, it can be noticed that the tensile strength of the $40 \mathrm{wt} \%$ nanofiber/PLA composite is lower than that of the $30 \mathrm{wt} \%$ nanofiber/PLA composite. The decrease in the tensile strength indicates that nanofibers' aggregation and poor dispersion will occur in the composite with high content of nanofibers. Different from the tensile strength, Young's modulus, bending strength (MOR), bending modulus (MOE), and impact toughness of four nanocomposites increase rapidly with increasing the loading of nanofibers. The dramatic improvement can be attributed to the excellent dispersion and improved interfacial interaction between nanofibers and PLA chains. Excellent dispersion of nanofibers leads to the formation of a network structure, which leads to significant improvement in mechanical strength. However, when the content of nanofiber is fixed, four composites show different mechanical properties. The poplar CNFs/PLA composite exhibits the best mechanical properties and the prawn shell CHNFs/PLA composite shows the second highest 


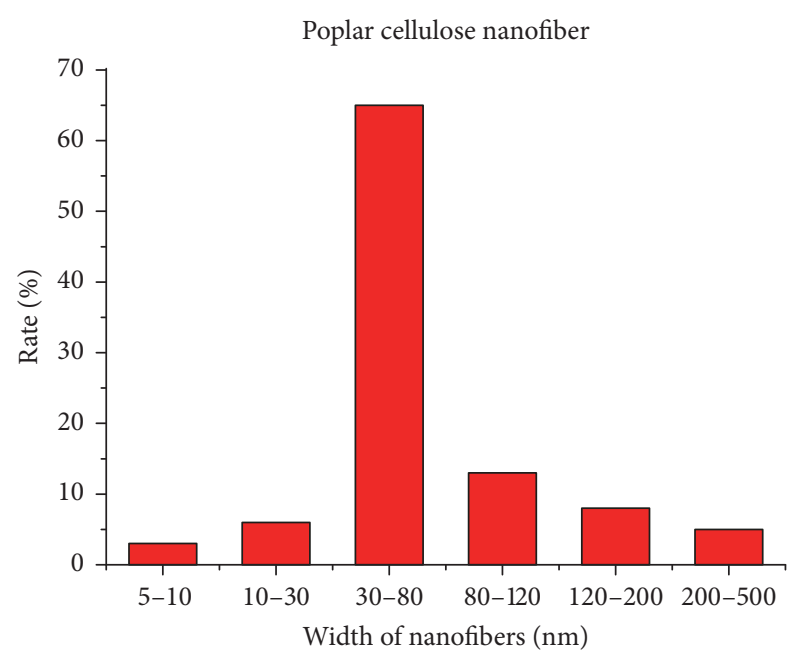

(a)

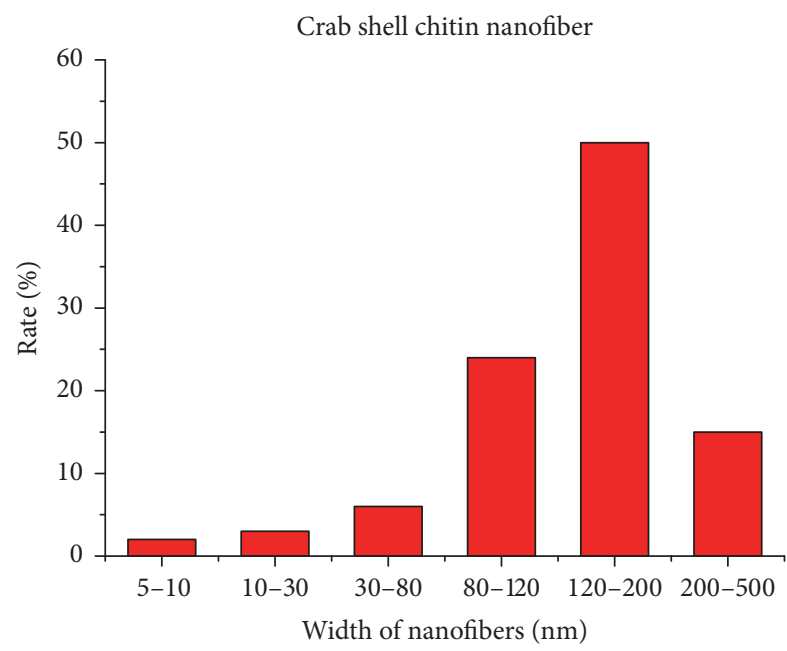

(c)

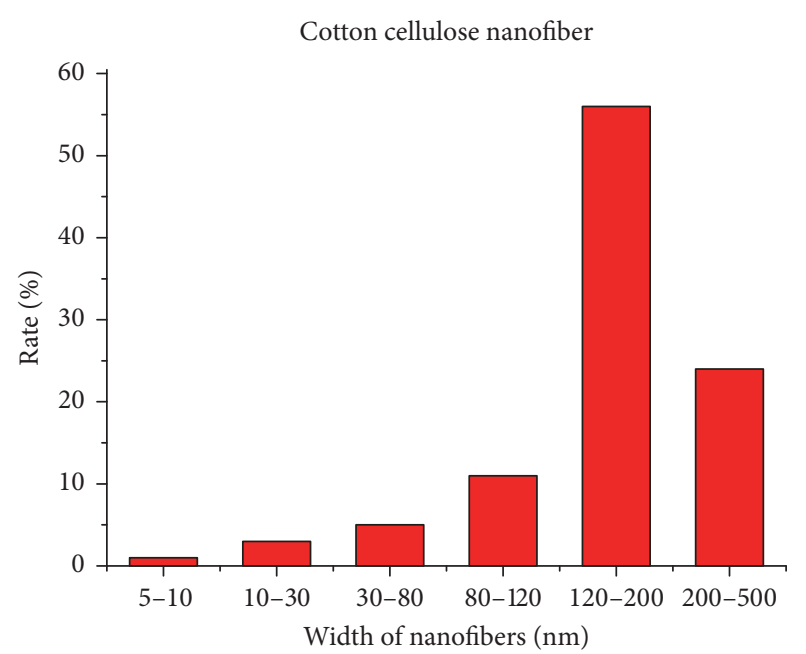

(b)

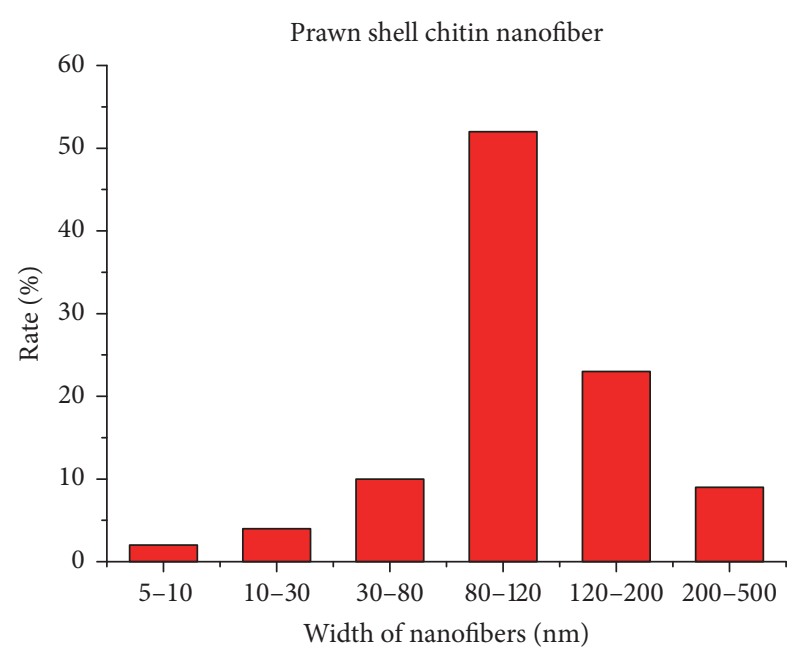

(d)

FIgURE 2: Diameter distribution of the nanofibers extracted from original (a) poplar, (b) cotton, (c) crab shell, and (d) prawn shell.

mechanical strength among four nanocomposites. The mechanical properties of cotton CNFs/PLA composite and the crab shell CHNFs/PLA composite are the worst. The excellent mechanical performance of the poplar CNFs/PLA composite is ascribed to the highest aspect ratio of poplar CNFs. So it can be concluded that the aspect ratio of nanofibers is the main reason for different mechanical properties of the nanocomposites, whether raw material is cellulose or chitin. Rowell and coworkers reported that a high aspect ratio is very important in fiber reinforced composites, as it indicates potential strength properties [30]. Stark and Rowlands reported that aspect ratio, rather than particle size, has the greatest effect on strength and stiffness [31]. The mechanical properties of the fiber/polymer composites are determined by several factors, such as nature of the reinforcement fiber, fiber aspect ratio, fiber-matrix interfacial adhesion, and also the fiber orientation in the composites [32]. Except for the factor of fiber aspect ratio, the interfacial adhesion and fiber dispersion are also very important factors to influence the reinforcing effect of fibers. The improvements of mechanical properties demonstrate that homogeneous dispersion of CNFs/CHNFs could be achieved by using the water preblending method. Furthermore, the excellent impact toughness of the nanocomposites could be obtained due to the ultralong CNFs/CHNFs. If the nanofibers are uniformly dispersed in the matrix, the refined nanofibers network structure can absorb a large amount of energy in the process of fracture, leading to a great improvement in impact strength of the nanocomposite.

FE-SEM. FE-SEM micrographs of fractured surfaces of four different nanofibers reinforced PLA composites are presented in Figure 5. Homogeneous dispersion of nanofibers in PLA matrix could be achieved for all four samples with the water preblending method. It is observed that lots of ultralong and refined nanofibers are distributed uniformly and compactly on the fracture surface of the nanocomposite in the form of a "spider web" without aggregation. The cellulose/chitin 


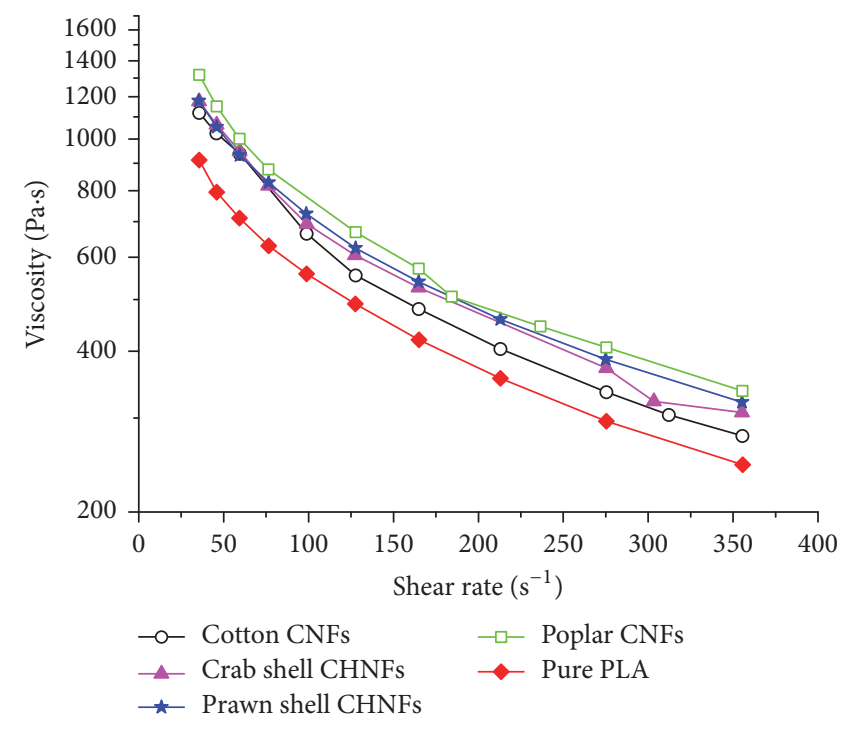

(a)

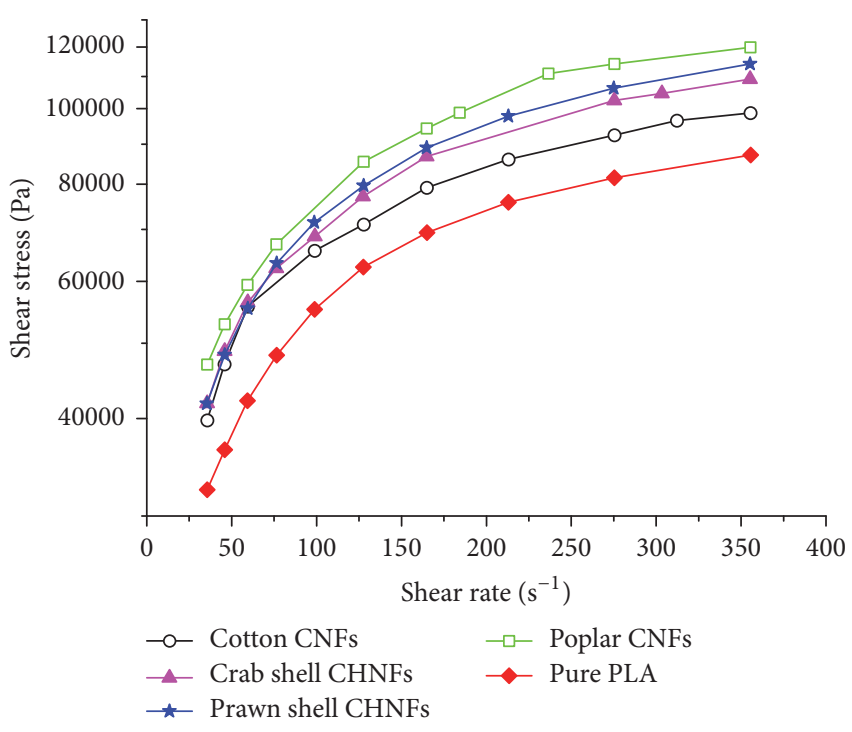

(b)

FIGURE 3: The viscosity and shear stress of four nanofibers/PLA composites as functions of shear rate.

nanofibers in the composites have the same entangled structure as the nanofibers, which means that the network structure of the nanofibers is stable and unaltered even after the water preblending and extrusion processes. The rough fracture surface suggests that large plastic deformation has occurred in the process of the fracture instead of the brittle fracture mode for the neat PLA. The fiber bundles disruption and delamination take more energy as compared to fiber fracture, leading to the prolonged crack propagation before failure. This mechanism is responsible for high toughness in the nanofiber/PLA composite. For the water pretreatment method, hydrophilic nanofiber and hydrophobic PLA fibers can be uniformly dispersed in aqueous suspension [33]. During the preblending process, nanofibers are adsorbed on PLA fiber and entangled to form a net shape. Therefore, the formed electrostatic repulsion and steric hindrance between nanofibers and PLA result in the uniform dispersion of cellulose/chitin nanofibers.

From the SEM images, it can be found that there are distinct differences in the fiber diameter and length for four samples. The poplar CNFs in the PLA matrix are the most homogeneous, having the lowest fiber diameter and highest length. These finer and longer fibers have higher resistance to deformation under the vacuum applied and develop greater network strength. The prawn shell CHNFs/PLA sample is intermediate between the poplar sample and the crab shell/cotton samples, as it contains some thicker fibers compared to poplar CNFs but finer fibers compared to crab shell/cotton nanofibers. For the crab shell/cotton nanofibers, both samples have some large fiber bundles; thus the samples are highly heterogeneous. This is because the strong hydrogen bonding between the nanofiber bundles makes it difficult to obtain thin and uniform nanofibers from crab shell/cotton. The fiber bundles with low aspect ratio lead to relatively low mechanical properties of the nanocomposites.
Coefficient of Thermal Expansion (CTE). The reinforcement effect of fibers can also be characterized to analyze the thermal expansion of plastics examined using the TMA. As reported, thermal expansion has an inverse relationship with Young's modulus [33]. The CTE values of four different nanocomposites and sheets prepared by different raw materials are presented in Figure 6. The CTE value of neat PLA is up to $180 \times 10^{-6} \mathrm{~K}^{-1}$ due to its amorphous flexible molecular chains (Figure 6(a)). The thermal expansion of PLA was remarkably suppressed by the introduction of $\mathrm{CHNFs/CNFs.}$ The CTE values of the composites with $40 \mathrm{wt} \%$ nanofibers extracted from poplar, cotton, crab shell, and prawn shell are $69.5 \times 10^{-6} \mathrm{~K}^{-1}, 79.6 \times 10^{-6} \mathrm{~K}^{-1}, 77.2 \times 10^{-6} \mathrm{~K}^{-1}$, and $75.3 \times 10^{-6} \mathrm{~K}^{-1}$, respectively. CNFs/CHNFs with low CTE and high Young's modulus can effectively decrease the thermal expansion of PLA matrix due to the reinforcement effect, resulting from the suppression of the expansion for PLA matrix by the rigid three-dimensional nanostructural networks of nanofibers at high temperature [34]. On the other hand, the reinforcement effect can be attributed to the homogeneous dispersion of nanofibers in PLA matrix with the water preblending method. It can also be found that the poplar CNFs/PLA composite shows the lowest thermal expansion and the cotton CNFs/PLA composite shows the highest thermal expansion. In addition, it can be noticed that the CTE value of the crab shell CHNFs/PLA composite is slightly lower than that of cotton CNFs/PLA composite, which is different from the result of mechanical properties. This phenomenon can be explained by the fact that chitin nanofibers have higher thermal stability and higher crystallinity than cellulose nanofibers [14]. Furthermore, the CTE values of nanofibers sheets were measured in the same temperature region. From Figure 6(b), it can be seen that CTE values of the sheets made from poplar, cotton, crab shell, and prawn shell are $36.9 \times 10^{-6} \mathrm{~K}^{-1}, 45.7 \times 10^{-6} \mathrm{~K}^{-1}, 36.4 \times$ 


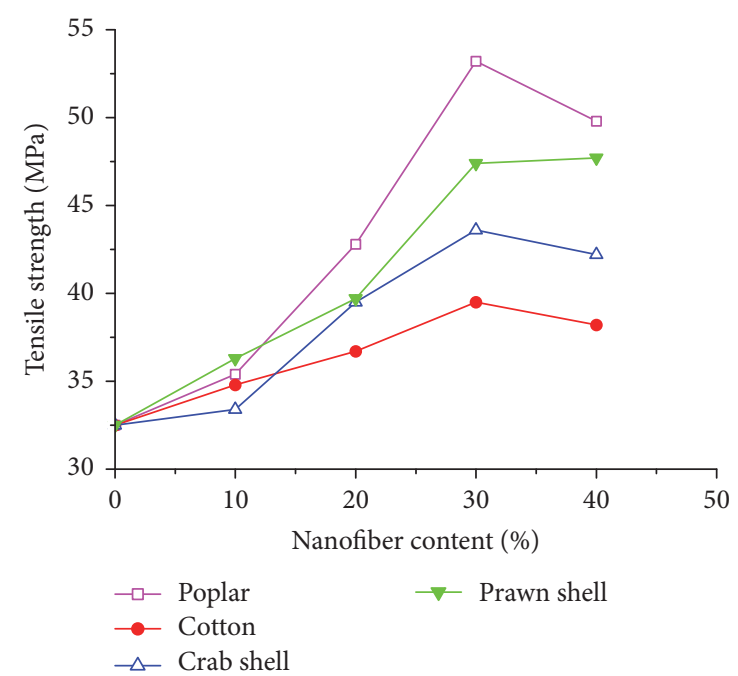

(a)

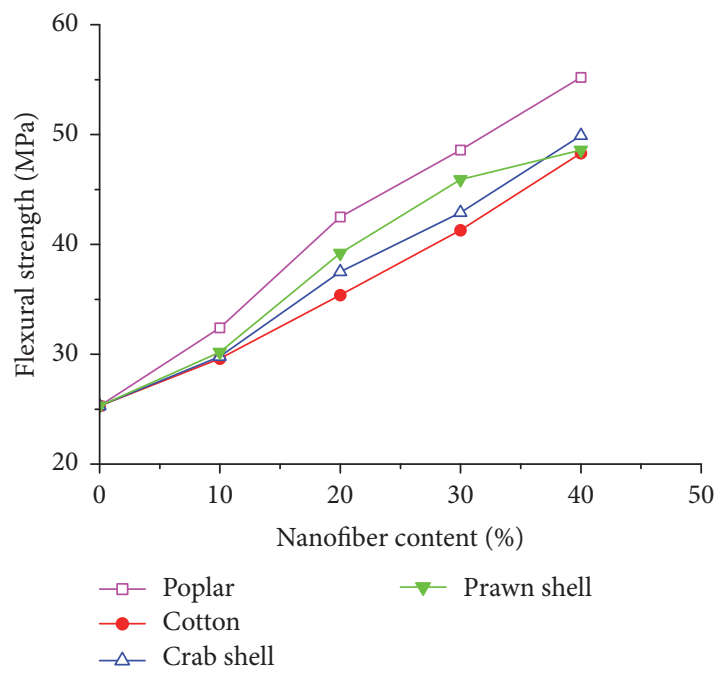

(c)

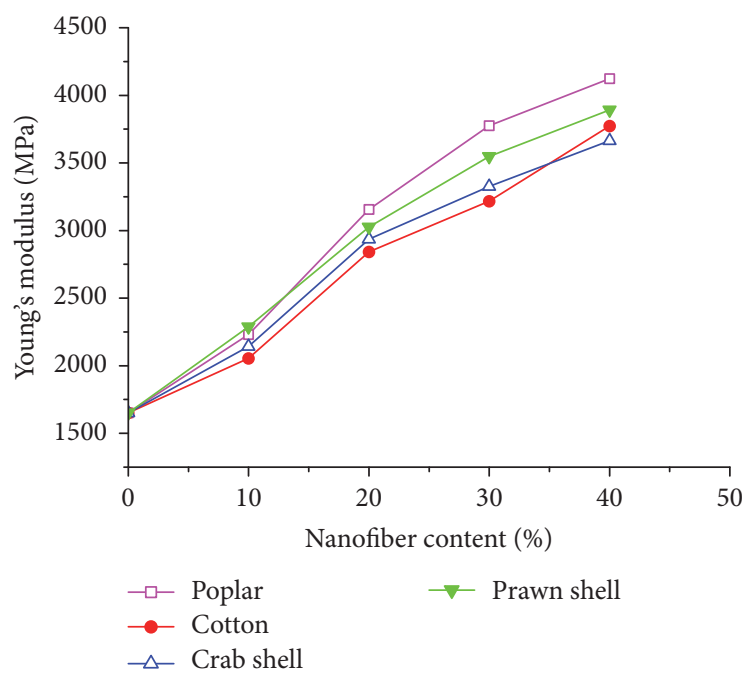

(b)

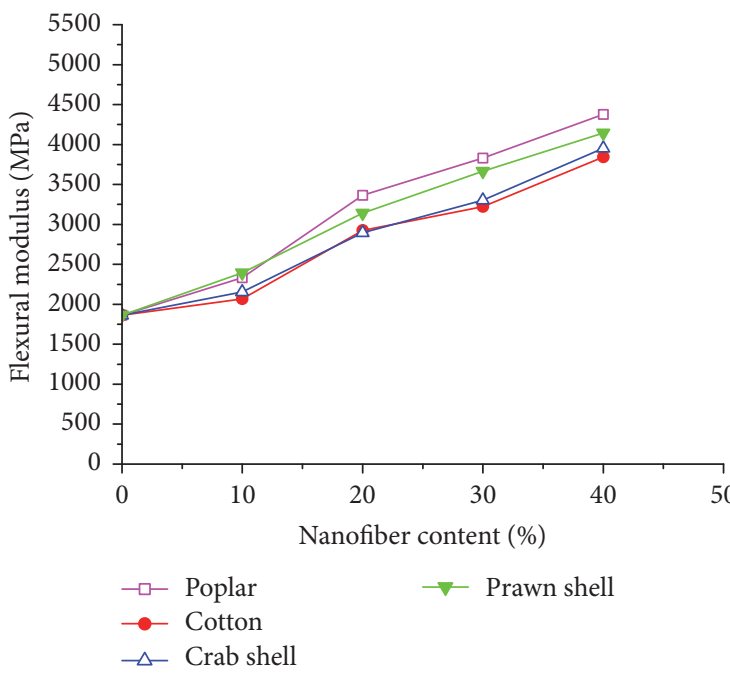

(d)

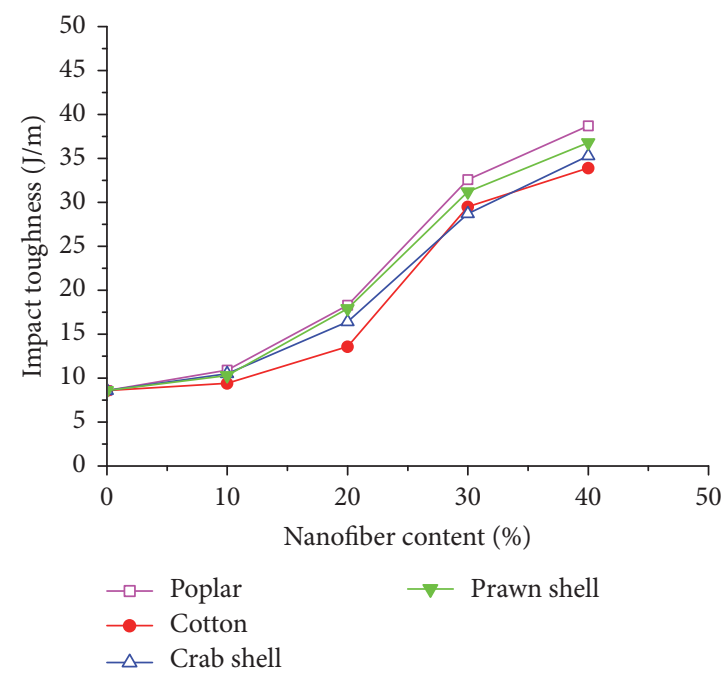

(e)

Figure 4: The mechanical properties, (a) tensile strength, (b) Young's modulus, (c) flexural strength, (d) flexural modulus, and (e) impact toughness of four nanofibers/PLA composites as functions of nanofiber content. 


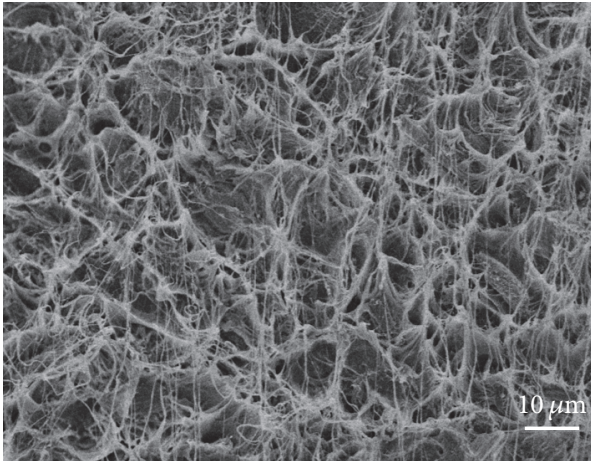

(a)

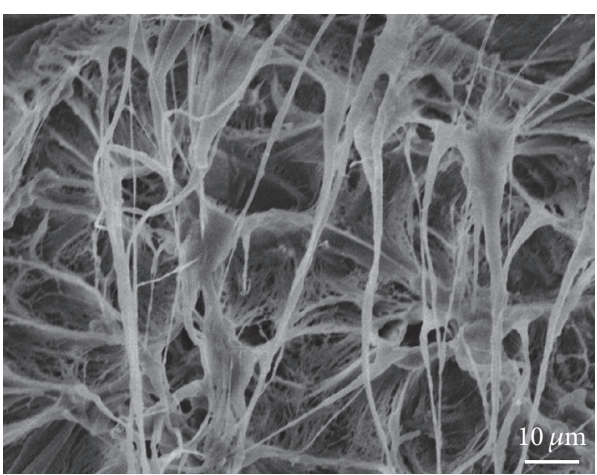

(c)

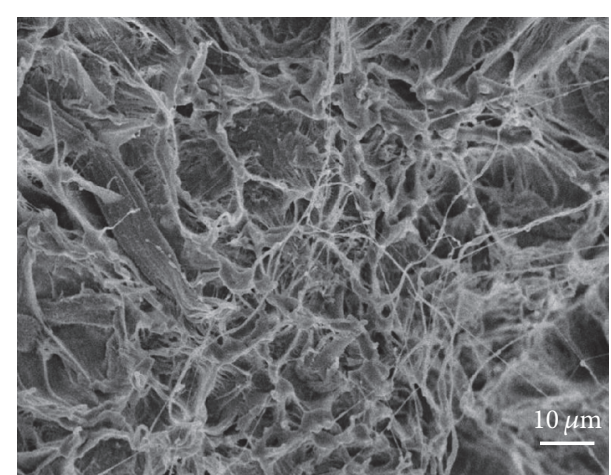

(b)

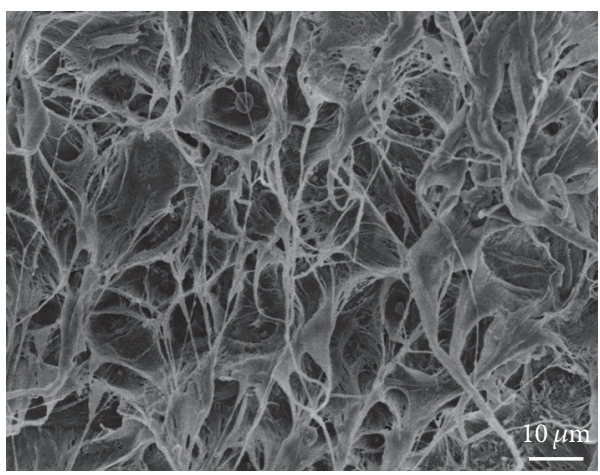

(d)

Figure 5: The FE-SEM images of fracture surfaces for $40 \mathrm{wt} \%$ nanofibers/PLA composites: (a) poplar CNFs, (b) cotton CNFs, (c) crab shell CHNFs, and (d) prawn shell CHNFs.

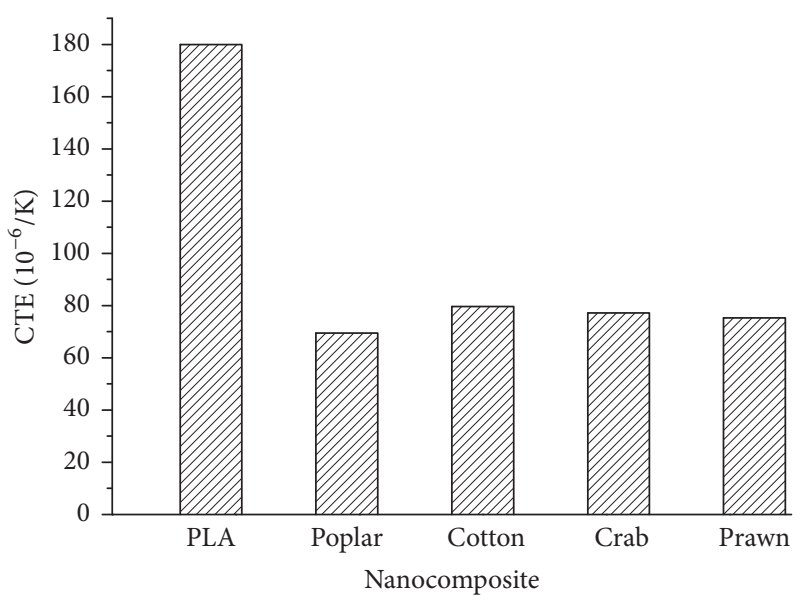

(a)

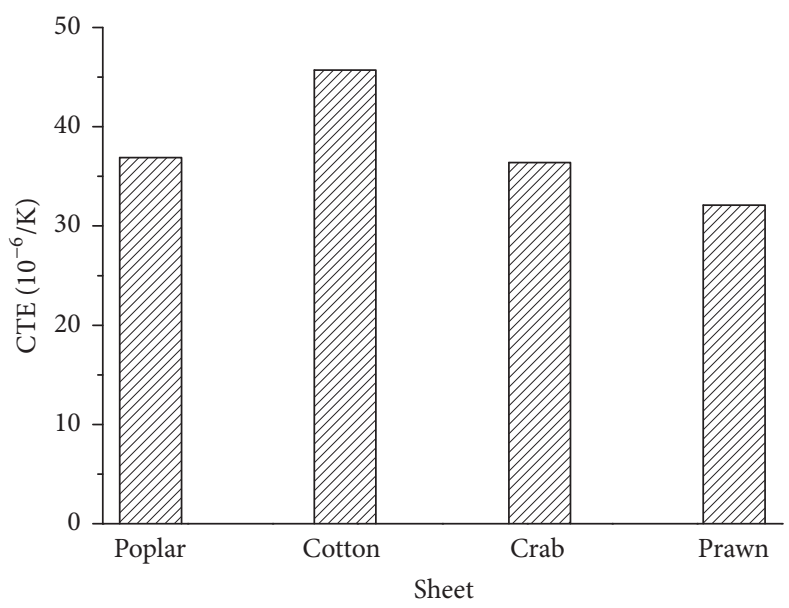

(b)

FIgURE 6: CTE values of (a) nanofibers/PLA composites and (b) nanofiber sheets.

$10^{-6} \mathrm{~K}^{-1}$, and $32.1 \times 10^{-6} \mathrm{~K}^{-1}$, respectively. CHNFs sheets have lower thermal expansion than that of CNFs sheets. Hence, the crab shell CHNFs/PLA composite presents lower CTE value than the cotton CNFs/PLA composite. In addition, it can be noticed that the CTE value of the crab shell CHNFs sheet is approximately equal to that of the poplar CNFs sheet, but the poplar CNFs/PLA composite shows much lower thermal expansion than that of crab shell CHNFs/PLA composite.
This result can be ascribed to the fact that poplar CNFs have much higher aspect ratio than the crab shell CHNFs, leading to higher mechanical properties. Therefore, it can be concluded that the aspect ratio of fibers has great influence on the thermal expansion of the polymer matrix.

DMA. Dynamic mechanical test methods have been widely employed for investigating the structures and viscoelastic 


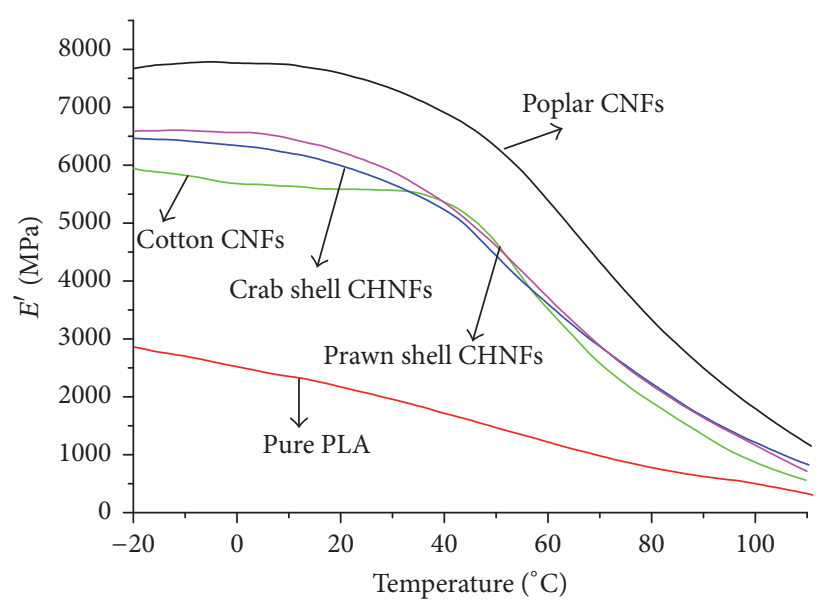

(a)

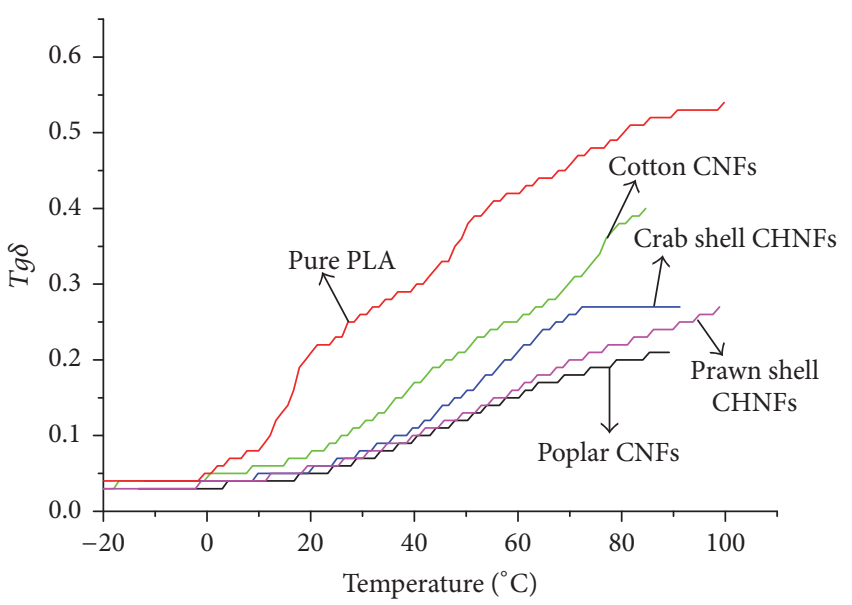

(b)

FIGURE 7: Temperature dependence on (a) storage modulus $\left(E^{\prime}\right)$ and (b) loss factor $(\tan \delta)$ of four nanofibers/PLA composites at fiber content of $40 \mathrm{wt} \%$.

behavior of polymeric materials to determine their stiffness and damping characteristics for various applications. Figure 7 represents the plots of storage modulus $\left(E^{\prime}\right)$ and loss factor $(\tan \delta)$ with respect to temperature for the four nanofibers/PLA composites. In Figure 7(a), all the nanocomposites exhibit the storage modulus in the following order in the glassy region: poplar CNFs/PLA > prawn shell CHNFs/PLA > crab shell CHNFs/PLA > cotton CNFs/PLA. The storage modulus in the glassy state is primarily determined by the strength of the intermolecular forces and the way of the polymer chains packed by fibers [35]. High $E^{\prime}$ value can be attributed to the high interfacial adhesion and high aspect ratio of nanofibers, which may be helpful to the stress transfer in the nanofiber-matrix interface [36]. $\tan \delta$ is a dimensionless parameter that measures the ratio of loss modulus to storage modulus. For fibers/polymer composites, the loss of energy mainly occurs on the interface of fibers and polymers; thus high strength of composites indicates the low energy loss and low $\tan \delta$ [37]. In contrast, four nanocomposites exhibit $\tan \delta$ in the following order (Figure 7(b)): cotton CNFs/PLA > crab shell CHNFs/PLA $>$ prawn shell CHNFs/PLA > poplar CNFs. An increase in $\tan \delta$ among different composites indicates that the viscosity of the composite is improved. The DMA results indicate that the aspect ratio of the nanofibers has a great influence on the thermal and mechanical performance of the composites, irrespective of the composites prepared by cellulose or chitin.

\section{Conclusions}

Polylactic acid (PLA) was reinforced with ultralong cellulose and chitin nanofibers extracted from four raw materials by the extrusion molding. The poplar CNFs/PLA composite exhibited the best mechanical properties among four nanocomposites, while both the cotton CNFs/PLA composite and the crab shell CHNFs/PLA composite had low mechanical strength. Rheological measurement indicated that the viscosity and shear stress of the poplar CNFs/PLA composite are the highest among four samples, and the corresponding values of the cotton/PLA composite are the lowest. FE-SEM images showed that homogeneous dispersion of nanofibers in PLA matrix can be achieved with the water preblending method. The CTE values of the nanocomposites with $40 \mathrm{wt} \%$ nanofibers extracted from poplar, cotton, crab shell, and prawn shell were $69.5 \times 10^{-6} \mathrm{~K}^{-1}, 79.6 \times 10^{-6} \mathrm{~K}^{-1}, 77.2$ $\times 10^{-6} \mathrm{~K}^{-1}$, and $75.3 \times 10^{-6} \mathrm{~K}^{-1}$, respectively. The storage modulus of four nanocomposites in the glassy region is listed in the following order: poplar CNFs/PLA > prawn shell CHNFs/PLA > crab shell CHNFs/PLA > cotton CNFs/PLA. All the results indicated that the aspect ratio of the nanofibers has a great influence on the performance of the composites, irrespective of the composites prepared by cellulose or chitin.

\section{Disclosure}

Jingjing Li and Jian Li are co-first authors.

\section{Conflicts of Interest}

The authors declare that there are no conflicts of interest regarding the publication of this manuscript.

\section{Authors' Contributions}

Jingjing Li and Jian Li contributed equally to this work.

\section{Acknowledgments}

This work is financially supported by Ph.D. Start-up Fund of Northwest A\&F University (Z109021613). 


\section{References}

[1] I. Armentano, N. Bitinis, E. Fortunati et al., "Multifunctional nanostructured PLA materials for packaging and tissue engineering," Progress in Polymer Science, vol. 38, no. 10-11, pp. 17201747, 2013.

[2] M. M. Reddy, S. Vivekanandhan, M. Misra, S. K. Bhatia, and A. K. Mohanty, "Biobased plastics and bionanocomposites: current status and future opportunities," Progress in Polymer Science, vol. 38, no. 10-11, pp. 1653-1689, 2013.

[3] H. Li and M. A. Huneault, "Effect of nucleation and plasticization on the crystallization of poly(lactic acid)," Polymer Journal, vol. 48, no. 23, pp. 6855-6866, 2007.

[4] R. Auras, B. Harte, and S. Selke, "An overview of polylactides as packaging materials," Macromolecular Bioscience, vol. 4, no. 9, pp. 835-864, 2004.

[5] D. Klemm, B. Heublein, H. P. Fink, and A. Bohn, "Cellulose: fascinating biopolymer and sustainable raw material," Angewandte Chemie, vol. 44, no. 22, pp. 3358-3393, 2005.

[6] I. Sakurada, Y. Nukushina, and T. Ito, "Experimental determination of the elastic modulus of crystalline regions in oriented polymers," Journal of Polymer Science, vol. 57, no. 165, pp. 651660, 1962.

[7] T. Nishino, I. Matsuda, and K. Hirao, "All-cellulose composite," Macromolecules, vol. 37, no. 20, pp. 7683-7687, 2004.

[8] J. Jin, P. Hassanzadeh, G. Perotto et al., "A biomimetic composite from solution self-assembly of chitin nanofibers in a silk fibroin matrix," Advanced Materials, vol. 25, no. 32, pp. 4482-4487, 2013.

[9] J.-B. Zeng, Y.-S. He, S.-L. Li, and Y.-Z. Wang, "Chitin whiskers: An overview," Biomacromolecules, vol. 13, no. 1, pp. 1-11, 2012.

[10] W. Chen, K. Abe, K. Uetani, H. Yu, Y. Liu, and H. Yano, "Individual cotton cellulose nanofibers: pretreatment and fibrillation technique," Cellulose, vol. 21, no. 3, pp. 1517-1528, 2014.

[11] P. Dhar, D. Tarafder, A. Kumar, and V. Katiyar, "Thermally recyclable polylactic acid/cellulose nanocrystal films through reactive extrusion process," Polymer (United Kingdom), vol. 87, pp. 268-282, 2016.

[12] A. N. Frone, S. Berlioz, J.-F. Chailan, and D. M. Panaitescu, "Morphology and thermal properties of PLA-cellulose nanofibers composites," Carbohydrate Polymers, vol. 91, no. 1, pp. 377-384, 2013.

[13] N. Herrera, A. P. Mathew, and K. Oksman, "Plasticized polylactic acid/cellulose nanocomposites prepared using meltextrusion and liquid feeding: Mechanical, thermal and optical properties," Composites Science and Technology, vol. 106, pp. 149-155, 2015.

[14] N. Herrera, A. M. Salaberria, A. P. Mathew, and K. Oksman, "Plasticized polylactic acid nanocomposite films with cellulose and chitin nanocrystals prepared using extrusion and compression molding with two cooling rates: Effects on mechanical, thermal and optical properties," Composites Part A: Applied Science and Manufacturing, vol. 83, pp. 89-97, 2016.

[15] M. Jonoobi, J. Harun, A. P. Mathew, and K. Oksman, "Mechanical properties of cellulose nanofiber (CNF) reinforced polylactic acid (PLA) prepared by twin screw extrusion," Composites Science and Technology, vol. 70, no. 12, pp. 1742-1747, 2010.

[16] M. Kowalczyk, E. Piorkowska, P. Kulpinski, and M. Pracella, "Mechanical and thermal properties of PLA composites with cellulose nanofibers and standard size fibers," Composites Part A: Applied Science and Manufacturing, vol. 42, no. 10, pp. 15091514, 2011.
[17] L. Suryanegara, A. N. Nakagaito, and H. Yano, "The effect of crystallization of PLA on the thermal and mechanical properties of microfibrillated cellulose-reinforced PLA composites," Composites Science and Technology, vol. 69, no. 7-8, pp. 11871192, 2009.

[18] A. N. Nakagaito, K. Yamada, S. Ifuku, M. Morimoto, and H. Saimoto, "Fabrication of chitin nanofiber-reinforced polylactic acid nanocomposites by an environmentally friendly process," Journal of Biobased Materials and Bioenergy, vol. 7, no. 1, pp. 152-156, 2013.

[19] L. Tang, B. Huang, N. Yang et al., "Organic solvent-free and efficient manufacture of functionalized cellulose nanocrystals via one-pot tandem reactions," Green Chemistry, vol. 15, no. 9, pp. 2369-2373, 2013.

[20] A. M. Salaberria, J. Labidi, and S. C. M. Fernandes, "Chitin nanocrystals and nanofibers as nano-sized fillers into thermoplastic starch-based biocomposites processed by melt-mixing," Chemical Engineering Journal, vol. 256, pp. 356-364, 2014.

[21] R. Rizvi, B. Cochrane, H. Naguib, and P. C. Lee, "Fabrication and characterization of melt-blended polylactide-chitin composites and their foams," Journal of Cellular Plastics, vol. 47, no. 3, pp. 283-300, 2011.

[22] J. Li, D. Li, Z. Song, S. Shang, and Y. Guo, "Preparation and properties of wood plastic composite reinforced by ultralong cellulose nanofibers," Polymer Composites, vol. 37, no. 4, pp. 1206-1215, 2016.

[23] J. Li, Z. Song, D. Li, S. Shang, and Y. Guo, "Cotton cellulose nanofiber-reinforced high density polyethylene composites prepared with two different pretreatment methods," Industrial Crops and Products, vol. 59, pp. 318-328, 2014.

[24] J. Li, Y. Gao, J. Zhao, J. Sun, and D. Li, "Homogeneous dispersion of chitin nanofibers in polylactic acid with different pretreatment methods," Cellulose, vol. 24, no. 4, pp. 1705-1715, 2017.

[25] W. Chen, Q. Li, Y. Wang et al., "Comparative study of aerogels obtained from differently prepared nanocellulose fibers," ChemSusChem, vol. 7, no. 1, pp. 154-161, 2014.

[26] S. Ifuku and H. Saimoto, "Chitin nanofibers: Preparations, modifications, and applications," Nanoscale, vol. 4, no. 11, pp. 3308-3318, 2012.

[27] C. Miao and W. Y. Hamad, "Cellulose reinforced polymer composites and nanocomposites: a critical review," Cellulose, vol. 20, no. 5, pp. 2221-2262, 2013.

[28] A. N. Frone, S. Berlioz, J.-F. Chailan, D. M. Panaitescu, and D. Donescu, "Cellulose fiber-reinforced polylactic acid," Polymer Composites, vol. 32, no. 6, pp. 976-985, 2011.

[29] P. Qu, Y. Gao, G.-F. Wu, and L.-P. Zhang, "Nanocomposites of poly(lactic acid) reinforced with cellulose nanofibrils," Bioresources, vol. 5, no. 3, pp. 1811-1823, 2010.

[30] R. M. Rowell, J. S. Han, and J. S. Rowell, "Characterization and factors effecting fiber properties," in Natural Polymers and Agrofibers Composites, pp. 115-134, 2000.

[31] N. M. Stark and R. E. Rowlands, "Effects of wood fiber characteristics on mechanical properties of wood/polypropylene composites," Wood and Fiber Science, vol. 35, no. 2, pp. 167-174, 2003.

[32] J. K. Sameni, S. H. Ahmad, and S. Zakaria, "Effects of processing parameters and graft-copoly(propylene/maleic anhydride) on mechanical properties of thermoplastic natural rubber composites reinforced with wood fibres," Plastics, Rubber and Composites, vol. 31, no. 4, pp. 162-166, 2002. 
[33] A. N. Nakagaito and H. Yano, "The effect of fiber content on the mechanical and thermal expansion properties of biocomposites based on microfibrillated cellulose," Cellulose, vol. 15, no. 4, pp. 555-559, 2008.

[34] H. Yousefi, M. Faezipour, S. Hedjazi, M. M. Mousavi, Y. Azusa, and A. H. Heidari, "Comparative study of paper and nanopaper properties prepared from bacterial cellulose nanofibers and fibers/ground cellulose nanofibers of canola straw," Industrial Crops and Products, vol. 43, no. 1, pp. 732-737, 2013.

[35] L. A. Pothan, Z. Oommen, and S. Thomas, "Dynamic mechanical analysis of banana fiber reinforced polyester composites," Composites Science and Technology, vol. 63, no. 2, pp. 283-293, 2003.

[36] M. M. Andrade-Mahecha, F. M. Pelissari, D. R. Tapia-Blácido, and F. C. Menegalli, "Achira as a source of biodegradable materials: isolation and characterization of nanofibers," Carbohydrate Polymers, vol. 123, pp. 406-415, 2015.

[37] P. Zugenmaier, "Materials of cellulose derivatives and fiberreinforced cellulose-polypropylene composites: Characterization and application," Pure and Applied Chemistry, vol. 78, no. 10, pp. 1843-1855, 2006. 

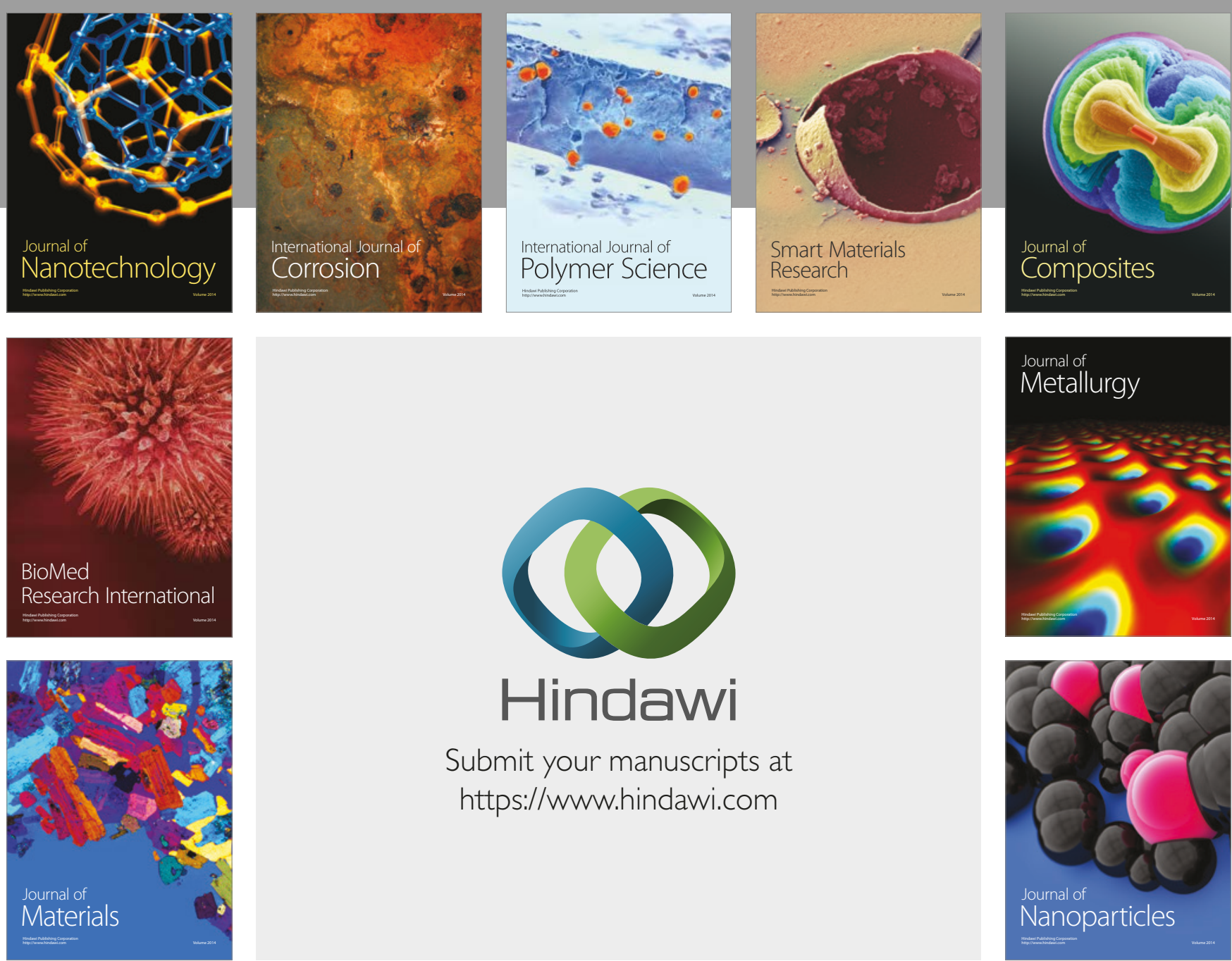

\section{Hindawi}

Submit your manuscripts at

https://www.hindawi.com
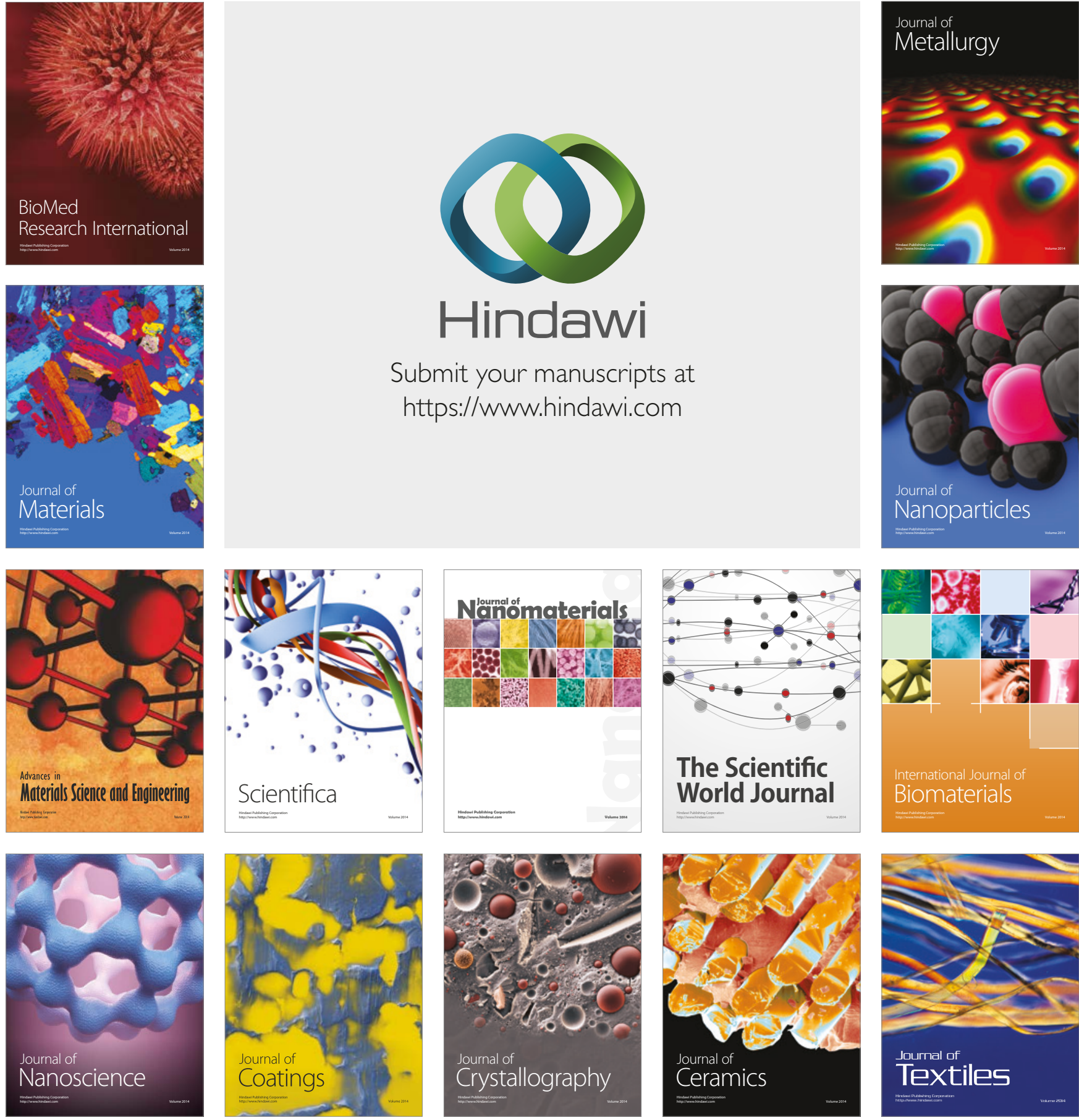

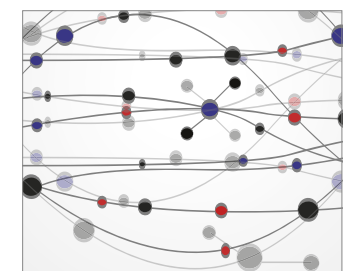

The Scientific World Journal
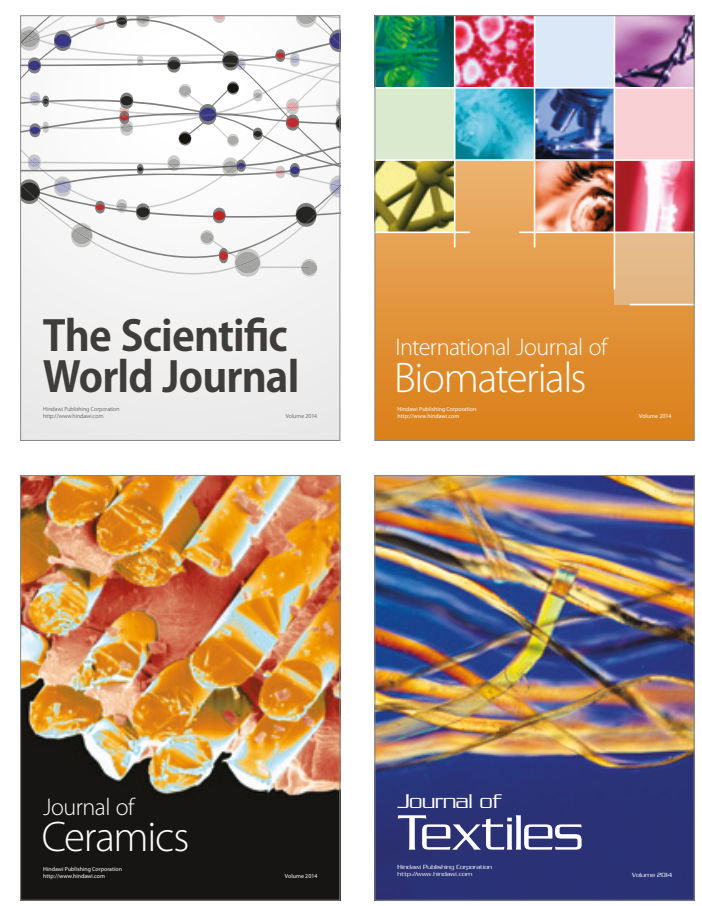